\title{
REFORMA CURRICULAR, FORMAÇÃO DOCENTE E EMANCIPAÇÃO HUMANA
}

\section{Valmir Pereira ${ }^{1}$}

RESUMO: Este estudo discute as relações entre a reforma curricular do Ensino Médio implementada pelo MEC na década de 1990 e suas vinculações com os pressupostos teóricos do modelo de organização do trabalho realizado pela Toyota, a Política de Formação docente e o processo de emancipação humana.

Palavras-chave: Reforma curricular. Ensino Médio. Pedagogia Toyota. Formação Docente. Emancipação Humana

RESUMEN: Este estudio discute las relaciones entre la reforma curricular de la Enseñanza Secundaria implementada por el MEC en la década de 1990 y sus vinculaciones con los presupuestos teóricos del modelo de organización del trabajo realizado por la Toyota, la Política de Formación docente y el proceso de emancipación humana.

Palabras-clave: Reforma curricular. Enseñanza Secundaria. Pedagogía Toyota. Formación Docente. Emancipación Humana.

\section{Introdução}

Inicialmente contextualizaremos a história das mudanças ocorridas no capitalismo, do período pós-guerra ao processo de reestruturação produtiva, a partir da década de 1970. Para isso, abordaremos as vinculações entre neoliberalismo, pós-modernismo e Toyotismo, considerando que fazem parte de uma totalidade que leva às alterações do capitalismo. Essas mudanças históricas, em nível produtivo e ideológico, constituem-se no pano de fundo das reformas educacionais empreendidas em vários países, mais notadamente naqueles em desenvolvimento como o Brasil.

As políticas educacionais brasileiras têm passado por revisões com 0 propósito de adequar o sistema educacional ao processo produtivo. Desse modo, trataremos também das mudanças ocorridas no cenário educacional, com destaque

\footnotetext{
${ }^{1}$ Docente e Coordenador do Curso de Filosofia da Universidade Estadual da Paraíba - UEPB e Líder do Grupo de Pesquisa em Ensino de Filosofia e Filosofia Marxista/CNPQ.provalmir@gmail.com
}

PEREIRA, Valmir. Reforma curricular, formação docente e emancipação humana. Revista Sul-Americana de Filosofia e Educação. Número 24: maio-out/2015, p. 313-334. 
para o Ensino Médio, cujas modificações se expressam nos Parâmetros Curriculares Nacionais do Ensino Médio (PCNEM).

A segunda metade da década de 1940 foi marcada pela reconstrução dos países arrasados pela II Guerra Mundial, pela internacionalização do capital, por um longo período de prosperidade e pela chegada de novas indústrias aos países periféricos, bem como por uma nova expansão do capitalismo em escala mundial e pela ascensão dos Estados Unidos como superpotência. Essas mudanças foram possíveis graças ao modelo de Estado adotado no período. O referido modelo foi organizado no início da década de 1930 e ficou conhecido como Welfare State, tendo por base as ideias do economista John Maynard Keynes (1883-1946). A respeito desse período, Groppo afirma que:

Os Estados passam a interferir na economia para garantir pleno
emprego, via taxa de juros insignificantes que estimulariam
empresas privadas a crescer e aumentar o número de seus
empregados, além da criação de estatais e iniciativas de obras
públicas que acolheriam trabalhadores. Preconizava-se, por fim, a
ajuda social aos desempregados. A questão do pleno emprego,
justificada por Keynes principalmente em termos macroeconômicos,
também teria seu lado sócio-político, já que se tratava também de
impedir a convulsão do sistema pelas lutas de classe e pela
revolução. Afinal, os exemplos dos socialismos eram reais - não
mais apenas opções teóricas. (GROPPO, 2005, p. 71 )

A adoção dessas políticas impediu o desemprego em massa e possivelmente uma revolução social, criando as bases para a sobrevivência do capitalismo do pósguerra, com crescimento significativo entre o final da II Guerra Mundial e a crise do petróleo, em 1973. Esse período experimentou, de fato, uma tranquilidade social duradoura.

No que se refere à organização da produção, o Estado vigente adotou o fordismo, pois o ritmo da fábrica ocupava corpos e mentes com a produção em série, padronizando produtos e comportamentos sociais. Desse modo:

[...] as classes trabalhadoras aceitavam a disciplina estrita no trabalho: a hierarquia, a vigilância, a perda total do controle do processo de trabalho etc. $\mathrm{O}$ advento do fordismo e do Estado de Bem-Estar levam ao extremo a "separação" entre as esferas da vida 
"pública" e privada, anunciado e realizado desde o início do capitalismo industrial. O trabalho torna-se o momento da disciplina $e$ da produtividade. O trabalhador "entrega-se" à rotina naquelas horas em que vende sua força de trabalho (GROPPO, 2005, p.72).

Ao possibilitar a produção em massa com uma mudança no nível de consumo de significativa parcela dos trabalhadores, o fordismo se identifica com o Estado de Bem-Estar Social, quando este garante os empregos e assegura direitos sociais, que mantêm o trabalhador conformado a essa ordem e, portanto, submisso à lógica do capital. No entanto, para que esse Estado paternalista subsista, são necessários recursos que possibilitem o atendimento das demandas por ele geradas. Esses recursos, porém, não são inesgotáveis e, apesar de ter atendido às exigências do capital no pós-guerra, o modelo keynesiano começa a dar sinais de esgotamento quando, a partir dos anos 1970:

[...] a queda da taxa de lucro, dada, dentre outros elementos causais, pelo aumento do preço da força de trabalho, conquistado durante o período pós-45 e pela intensificação das lutas sociais dos anos 60 , que objetivavam o controle social da produção. A conjugação desses elementos levou a uma redução dos níveis de produtividade do capital, acentuando a tendência decrescente da taxa de lucro; [...] a crise do welfare state ou do "Estado do BemEstar social" e dos seus mecanismos de funcionamento, acarretou a crise fiscal do Estado capitalista e a necessidade de retração dos gastos públicos e sua transferência para o capital privado. (ANTUNES, 2005, p. 29-30).

O agravamento da crise do modelo keynesiano, antes de se configurar numa crise geral do capitalismo, que pudesse levar a sua superação, serviu como fundamento para a reestruturação do capital que intensificou a exploração dos trabalhadores e acentuou as disparidades sociais.

A classe trabalhadora não ficou de espectadora desse processo e lutou por mais garantias sociais, maiores salários, democratização no processo de trabalho e, até certo ponto, pelo controle da produção. Reivindicações em escala crescente e redução dos lucros transformaram o mundo das fábricas numa bomba prestes a explodir. Por outro lado, a organização do trabalho, na perspectiva fordista, não 
atendia mais às necessidades de reprodução do capital na velocidade requerida por este modo de produção. Dessa forma, os altos índices de crescimento da produção capitalista chegaram ao fim. Por isso, a decadência do Estado de BemEstar Social e, ao mesmo tempo, a substituição do fordismo por modelos mais "flexíveis" de relações de produção começa a se espalhar pelo mundo. Como havia uma vinculação entre fordismo e Estado de Bem-Estar Social, ao esgotar-se o fordismo como modelo de organização do trabalho, esgota-se também o Welfare State como modelo de Estado.

Desse modo, o capital se reorganiza para manter seu padrão de acumulação por meio da reestruturação produtiva, que se dará, sobretudo, com a flexibilização das relações de trabalho e com a automação. A automação requer um trabalhador multifuncional e, assim, vai aos poucos substituindo as profissões especializadas do modelo fordista: conhecimentos únicos não são mais necessários e, para se manterem na fábrica, os trabalhadores precisam ter múltiplas habilidades. $\mathrm{O}$ perfil profissional exigido nas empresas passa a ser polivalente, com atuação em equipe, capacidade de tomar iniciativas, sem horário fixo, enfim, flexível.

\section{Globalização, Neoliberalismo e Pós-Modernismo}

Enquanto na organização da produção o fordismo começa a perder espaço para o Toyotismo, um novo modelo de Estado, aos poucos, se estabelece em oposição ao Estado de Bem-Estar Social. O Estado intervencionista atingiu seus limites, não mais detendo os conflitos sociais e, ao contrário, gerou novos conflitos que demonstravam a crise da legitimidade da sociedade capitalista. Por sua vez, diante da queda do crescimento econômico, que alimentava tanto os altos salários quanto os recursos do Estado de Bem-Estar Social e os rendimentos da burguesia, a classe social dominante reclama a necessidade de retomar a lucratividade. Assim, o capital se reestrutura e a divisão mundial do trabalho torna-se mais flexível, $e$ passa a expressar o movimento do modo de produção.

Essa forma de organização do capital é própria da chamada globalização do mundo, da economia, da cultura, dos valores, do desenvolvimento tecnológico, que são discutidos a partir de parâmetros não mais locais, ou nacionais, pois para 
eles não existem mais fronteiras. Tudo está em conexão com as transformações que vão ocorrendo em decorrência desse fenômeno. Assim, a globalização do capitalismo enfraqueceu o poder de controle da economia pelo Estado e, consequentemente, chegou-se ao Estado Mínimo, modelo de Estado que sucede o Welfare State, conhecido como Neoliberalismo.

O neoliberalismo é um fenômeno econômico e ideológico, característico do capitalismo. É uma manifestação fenomênica da sua globalização mais recente. Ele foi elaborado no final da década de 1940, como alternativa às ideias econômicas de Keynes e ao Estado de Bem-Estar Social. Friedrich Von Hayek (1899 - 1992) e Milton Friedman (1912-2006), ícones do neoliberalismo, argumentavam que o Estado estava muito grande e que portanto, deveria diminuir o seu tamanho para que os empresários pudessem desenvolver suas atividades, principalmente no setor econômico.

Nessa perspectiva, as quatro últimas décadas foram marcadas pela ascensão do neoliberalismo como proposta e realização do capital para adequar o conjunto das sociedades do Ocidente aos novos padrões de produção decorrentes do rápido e intenso desenvolvimento tecnológico estimulado durante o período do pósguerra. Considerado pelos seus proponentes como a única alternativa frente à crise de acumulação gerada durante a vigência do Estado de Bem-Estar Social, o neoliberalismo se traduz no fortalecimento dos ideais e práticas de auto regulação $e$ competição em todos os âmbitos da vida em sociedade, pois para o capital, o Estado executor de políticas sociais fracassou.

Ao cenário de mudanças no setor produtivo, no modelo de Estado e com a reestruturação do capitalismo vistos até aqui, acrescentamos um outro componente que fundamentará ideologicamente as transformações em curso, o PósModernismo, uma corrente de pensamento que está no campo das artes, da arquitetura e principalmente no das ciências humanas.

Originário da geração de 1960 e dos seus estudantes, o pós-modernismo é produto de uma consciência formada na idade áurea do capitalismo. Assim, a pósmodernidade é definida por ideias que negam os pressupostos epistemológicos que orientam o pensamento moderno, especialmente sua concepção de Ser humano. 
Mas como seria o homem da modernidade, rejeitado pelo pensamento pósmoderno? Segundo Rosenau:

O sujeito da modernidade é devotado ao seu trabalho, no qual procura dar o melhor de si, agindo com disciplina, planejamento e senso de responsabilidade; é compromissado com projetos políticos e objetivos ideológicos; acredita no livre-arbítrio e na autonomia pessoal, mas se submete à posição da maioria ou à linha do partido após votação $e$ deliberação; é capaz de subordinar suas vontades pessoais ao bem comum, ou seja, é capaz de agir em prol da coletividade; respeita regras e padrões coletivos que considerem justos; acredita na possibilidade de conhecer-se a verdade, confia na racionalidade e na ciência, colocando-as acima das emoções; é otimista em relação ao futuro da humanidade e ao progresso; vê a si mesmo como um ser humano que age com conhecimento de causa e possui uma identidade própria (ROSENAU, apud DUARTE, 2004, p.225).

Ao atacar o homem definido segundo os preceitos da modernidade, não significa que os autores pós-modernos não possuam uma compreensão do que seja o ser humano. Ao declarar a morte do sujeito da modernidade, qual a concepção de indivíduo que esses autores têm? Para Duarte:

(...) o indivíduo pós-moderno não é uma pessoa consciente, livre e autônoma. Sua existência é anônima. Trata-se de uma pessoa descontraída, flexível, que ouve seus sentimentos e emoções e procura aceitar a si mesma tal como é. Tem seu próprio estilo de vida, mas não procura ser exemplo para ninguém, pois não pretende possuir nenhuma verdade. Cultiva o senso de humor, a fantasia, a cultura do desejo e a gratificação imediata. Vive o presente e prefere aquilo que é passageiro, momentâneo, tendo horror ao que é estável e permanente. Valoriza a espontaneidade e vê com maus olhos a disciplina e o planejamento. Gosta do que é diferente, exótico, místico, proveniente de tradições do passado e daquilo que é local, singular e não do que é comum, generalizado e universal. Preocupa-se com sua própria vida pessoal e suas necessidades pessoais e não está interessado em laços com instituições tradicionais como família, Igreja, partido, nação etc. O indivíduo pós-moderno não possui uma forte identidade pessoal, é fragmentado, sem pontos fixos de referência e tolerante consigo mesmo. Está mais interessado na livre expressão, na dispersão e na diversidade do que na coerência, na concentração e na organização (DUARTE, 2004, p. 228). 
Identificados os postulados pós-modernos e a que eles se contrapõem, passamos aos impactos desses conceitos no campo da educação. A teoria educacional pós-moderna rejeita qualquer perspectiva objetiva de conhecimento, pois para ela o saber não é objetivo, mas subjetivo. Na esteira da rejeição, aparecem as grandes narrativas e a visão global e totalizante. A própria ideia de ensinar passou a ser sinônimo de atraso, pois é identificada como meta narrativa $e$ consequentemente vinculada a uma modernidade que não existe mais, segundo esses autores. Mas como um pós-moderno pode ensinar que não se deve ensinar? Não estaria ele fazendo o que não deve ser feito na sua concepção? Aquele pósmoderno não estaria sendo "moderno"? Ao argumentar para defender o ideário da pós-modernidade, está fazendo uso da "razão" para se fazer compreender. Ora, o uso da "razão", é próprio da modernidade, tão combatida por ele. Novamente está em contradição com o que defende, usando as mesmas estratégias que são identificadas como inviáveis para a sociedade pós-moderna e do conhecimento. Boa parte da produção dos autores pós-modernos foi escrita contra a "razão moderna de corte iluminista”. (MORAES, 2003, p.155)

O tratamento dado à razão pelo pensamento pós-moderno aproxima-se do ideário neoliberal. Butler, citando Hayek afirma que:

(...) é ilusão pensar que a razão humana é tão poderosa que nos permite pairar acima de nossa civilização e julgar nossas normas e valores de certo modo 'científico' ou objetivo, e que podemos produzir uma civilização melhor se replanejarmos completamente essas normas e valores. O máximo que podemos fazer é confrontar algumas normas da nossa civilização com a de outros lugares, para escolher as que preferimos. Isso porque nossa razão não é algo que está fora da sociedade ou desligada dos valores humanos; nossa mente evoluiu também como parte da civilização humana. Não planejamos nem podemos planejar a sociedade. Com certeza não temos inteligência suficiente para tanto (BUTLER, 1987, p.36).

Dados os limites deste trabalho, não desenvolveremos aqui uma abordagem mais profunda das vinculações do neoliberalismo com o postulado pós-moderno. No entanto, vale ressaltar a dificuldade de encontrar autores que defendem as ideias pós-modernas posicionando-se contra os efeitos perversos do capitalismo 
nas suas várias manifestações. Seria prematuro afirmar neste trabalho que o pensamento pós-moderno não se incomoda com o capitalismo. Entretanto, "o deus do irracionalismo convive muito bem com as multinacionais e com as 'razões' de Estado, com a desintegração do tecido social e a ausência de futuro para os milhões de exilados do mercado" (COSTA, 2004, p.78).

A quantidade de autores que se identificam com o pensamento pósmoderno é muito grande. Suas teorias estão em todos os lugares, principalmente nas escolas. Vale aqui destacar que as teorias formam o conjunto do conhecimento produzido pela humanidade ao longo de sua história. Independentemente de seu tempo e lugar, os homens produzem sua cultura. Ela é resultado das relações sociais e consequentemente do esforço do homem para produzir sua existência nas mais variadas formas. É o produto do seu trabalho. O trabalho deve ser compreendido como a atividade do homem em planejar e executar suas ações de modo que não só a força física produza, mas que esta seja resultado do seu pensamento, da sua racionalidade.

Apresentamos até aqui o cenário em que o capitalismo contemporâneo, ao se modificar e se reestruturar, passou a fazer ajustes em todos os setores da sociedade. A globalização, o neoliberalismo e o pós-modernismo compõem um conjunto de ajustes que agora se voltam para o setor educacional, por meio das reformas em suas políticas.

\section{Reforma educacional: ajustes às recomendações internacionais.}

A reforma na Educação Básica no Brasil, não deve ser vista como um caso isolado. Ela é decorrente das mudanças no âmbito do capitalismo contemporâneo que passou por ajustes significativos a partir da década de 1970, produzindo um conjunto de modificações no campo da política, da ideologia, da produção de mercadorias, na tecnologia e principalmente nas relações sociais. Por isso, essa reforma deve ser compreendida na perspectiva das mudanças paradigmáticas em nível planetário, solicitado pelo modo de produção capitalista.

As relações no âmbito da produção mudaram $e$ a formação dos trabalhadores continuava a mesma. Segundo a nova ordem capitalista, era 
necessário operar mudanças substantivas na qualificação dos trabalhadores para garantir o fluxo da produção de mercadorias, com o objetivo de atender o mercado global.

A educação considerada adequada para essa nova configuração social pode ser encontrada no Relatório da UNESCO, intitulado: Educação: um tesouro a descobrir, organizado por Jacques Delors. Esse documento é resultado da Conferência Mundial de Educação para Todos, que ocorreu na Tailândia, em 1990 e foi convocada pela UNESCO, Unicef, PNUD e Banco Mundial. Por isso, as reformas educacionais nos países em desenvolvimento, dentre eles o Brasil, ocorreram em conformidade com os mesmos pressupostos.

A influência da UNESCO na reforma educacional brasileira é bastante visível, pois ao analisarmos o Relatório da UNESCO e os PCN do Ensino Fundamental do MEC, encontramos algumas similaridades. A primeira aparece quando o documento da UNESCO afirma que é preciso superar algumas tensões, dentre elas, "a tensão entre o global e o local: tornar-se, pouco a pouco, cidadão do mundo sem perder as suas raízes e participando, ativamente, na vida do país e das comunidades de base" (DELORS, 2006, p.14). A aplicação desse conteúdo nos documentos oficiais no Brasil ficou com a seguinte redação: "A tensão entre o global e o local, ou seja, entre tornar-se pouco a pouco cidadão do mundo sem perder suas raízes, participando ativamente da vida de sua nação e de sua comunidade" (BRASIL, 1998, p.16). Essa exposição por si só já demonstra que os PCN do Ensino Fundamental estão em estreita relação com as propostas educacionais do mundo globalizado. Mas é interessante notarmos que, no decorrer do texto, essa semelhança torna-se mais evidente quando o Relatório insiste em apontar as tensões a serem ultrapassadas:

[...] a tensão entre o universal e o singular; [...] a tensão entre tradição e modernidade; [...] a tensão entre as soluções a curto e a longo prazo, tensão eterna [...]; a tensão entre a indispensável competição e o cuidado com a igualdade de oportunidades [...]; a tensão entre o extraordinário desenvolvimento dos conhecimentos e as capacidades de assimilação do homem [...]; a tensão entre o espiritual e o material. (DELORS, 2006, p. 14-15). 
Novamente, a redação dada nos PCN sofreu mudanças na forma, mas não no seu conteúdo: "A tensão entre o universal e o singular; [...] a tensão entre a cultura local e a modernização dos processos produtivos; [...] a tensão entre o instantâneo/efêmero e o durável; [...] a tensão entre o espiritual e o material" (BRASIL, 1998, p.16). A partir dessas semelhanças, é possível verificar o que afirmamos anteriormente, ou seja, que os PCN estão em conexão com as mudanças propostas pelo capitalismo mundial, que se baseiam principalmente na reestruturação produtiva.

A proposta do Relatório da UNESCO e dos PCN, além das semelhanças apontadas, trazem, em seu corpo, conceitos que são fundamentais para compreender as mudanças em curso e o novo modelo de sociedade a ser construído. Desses conceitos, o de cidadania e o de formação para o trabalho compõem o fio condutor da reforma educacional brasileira, bem como das reformas empreendidas em vários países em desenvolvimento. A cidadania e a formação para o trabalho são conceitos que passaram a ocupar o centro das políticas educacionais no Brasil a partir do Relatório da UNESCO. Refletindo sobre essa questão, Delors afirma que:

A educação ao longo de toda a vida torna-se assim, para nós, o meio de chegar a um equilíbrio mais perfeito entre trabalho $e$ aprendizagem bem como ao exercício de uma cidadania ativa [...] O mundo do trabalho constitui, igualmente, um espaço privilegiado de educação. Trata-se, antes de mais nada, da aprendizagem de um conjunto de habilidades $e$, a este respeito, importa que seja mais reconhecido, na maior parte das sociedades, o valor formativo do trabalho, em particular quando inserido no sistema educativo (DELORS, 2006, p. 105-113- grifo nosso)

Exercício da cidadania e formação para o trabalho são incorporados pela LDBEN e se transformam nos objetivos da Educação Básica. Adotando princípios do Relatório da UNESCO, a LDBEN também considera que a Educação Básica devem formar o cidadão e o trabalhador. Nessa perspectiva, o que será ensinado é tratado com muito cuidado em um currículo repleto de valores, apontando que ser 
cidadão é respeitar as diferenças do outro, dos povos e saber tanto seus direitos quanto seus deveres.

As mudanças nas políticas educacionais que ocorrem nos países da América Latina, especialmente na Educação Básica, podem ser encontradas nos PCNEM, conforme destaca o documento:

O Brasil, como os demais países da América Latina, está empenhado em promover reformas na área educacional que permitam superar o quadro de extrema desvantagem em relação aos índices de escolarização e de nível de conhecimento que apresentam os países desenvolvidos (BRASIL, 1999, p.15)

A ideia de que o índice de escolarização brasileira está em desvantagem em relação aos países desenvolvidos, esconde o fato de que o capitalismo se reestruturou e, dessa forma, o processo produtivo foi modificado e, agora, a escola precisa mudar, pois "[...] a educação é pensada sempre em decorrência do perfil do novo trabalhador fabril, das metamorfoses do mundo do trabalho, da empregabilidade, da crise econômica, etc." (ARROYO, 1999, p.18).

Um dos aspectos que nos chama a atenção, nos PCNEM é a parte intitulada o papel da educação na sociedade tecnológica (BRASIL, 1999, p.23). Nela o conhecimento é colocado como centro no processo produtivo e na organização social. A disciplina, a obediência e o respeito às regras estabelecidas não possuem mais nenhuma relevância para a inclusão social, face às novas exigências colocadas pelo desenvolvimento tecnológico e social. Na mesma linha de raciocínio, o documento em estudo revela a verdadeira "centralidade" do conhecimento ao afirmar que:

Não se pode mais postergar a intervenção no Ensino Médio, de modo a garantir a superação de uma escola que, ao invés de se colocar como elemento central de desenvolvimento dos cidadãos, contribui para a sua exclusão. Uma escola que pretende formar por meio da imposição de modelos, de exercícios de memorização, da fragmentação do conhecimento, da ignorância dos instrumentos mais avançados de acesso ao conhecimento $e$ da comunicação. [...] Não há o que justifique memorizar conhecimentos que estão sendo 
superados ou cujo acesso é facilitado pela moderna tecnologia [...] desbastar o currículo enciclopédico, congestionado de informações, priorizando conhecimentos e competências de tipo geral, que são pré-requisito tanto para a inserção profissional mais precoce quanto para a continuidade de estudos, entre as quais se destaca a capacidade de continuar aprendendo (BRASIL, 1999, p.24-25-87grifo nosso).

Embora o conhecimento tenha sido indicado anteriormente como centro do processo produtivo e organizador da sociedade, ele se torna agora o grande mal da sociedade e responsável pelo atraso do Brasil em relação aos países desenvolvidos. A solução proposta pelo neoliberalismo, pós-modernismo, globalização, enfim, pelo capitalismo contemporâneo por meio dos PCNEM é, na realidade, a renúncia aos conteúdos escolares. Essa renúncia aos conteúdos faz com que os alunos saibam menos para atuar num mundo cada vez mais exigente. De fato, o elevado nível de competitividade ampliou a demanda por conhecimentos e informações e, em decorrência, a educação foi eleita estratégica diante da velocidade das mudanças impostas pelos novos padrões de acumulação do modo de produção capitalista. A postura dos partidários do novo ideário escolar é clara: não basta apenas educar, é preciso assegurar o desenvolvimento de competências.

Desbastar o currículo significa fazer renúncias e estas referem-se ao conhecimento teórico. Atualmente, na educação, a teoria está desprestigiada e cede espaço para a prática que se dedica ao mundo imediato, no qual a reflexão teórica é a grande ausente. Para Moraes é a instalação do processo do recuo da teoria:

Meu argumento é o de que, no mais das vezes, a discussão teórica tem sido gradativamente suprimida das pesquisas educacionais, com implicações políticas, éticas e epistemológicas que podem repercutir, de curto e médio prazos, na própria produção de conhecimento na área. A celebração do "fim da teoria" movimento que prioriza a eficiência e a construção de um terreno consensual que toma por base a experiência imediata ou o conceito corrente de "prática reflexiva" - se faz acompanhar da promessa de uma utopia educacional alimentada por um indigesto pragmatismo. Em tal utopia praticista, basta o know-how e a teoria é considerada perda de tempo ou especulação metafísica e, quando não, restrita a 
uma oratória persuasiva e fragmentária, presa à sua própria estrutura discursiva (MORAES, 2003, p.153-154).

Com a redução e o empobrecimento dos conteúdos no novo currículo, conforme proposta dos PCNEM, o papel do professor, como transmissor dos conhecimentos produzidos $e$ acumulados pela humanidade, fica relegado a segundo plano. Se a transmissão do saber escolar é tão nociva ao ser humano, por que razão a proposta é pela redução e não pela sua supressão? Ora, a burguesia está empenhada em tornar este saber, que é produzido socialmente, propriedade exclusivamente sua, pois isso garante seu poder. No entanto, a classe social dominante permite que o trabalhador adquira algum tipo de saber, sem o qual ele não poderia produzir.

Neste sentido, a questão primordial que se coloca para os trabalhadores é a do acesso ao conhecimento que lhes permita compreender a sociedade capitalista e seu movimento. É esse conhecimento que lhes assegurará a possibilidade de superar as limitações dos conhecimentos fundamentais de que dispõem no dia a dia, tanto os científicos quanto os humanísticos e o domínio teórico que lhes permita apreender a totalidade em pensamento. Por isso, os PCNEM, ao proporem o desbaste do currículo estão a serviço da classe dominante e, consequentemente, auxiliando o capital a se desenvolver, aprofundando a desigualdade e a exclusão social.

O papel do professor é garantir que o conhecimento seja apropriado pelos seus alunos, pois quanto mais informações eles tiverem, mais possibilidades de fazer opções eles terão. E o papel da escola é "possibilitar o acesso das novas gerações ao mundo do saber sistematizado". (SAVIANI, 1991, p.80). No entanto, não é esse o entendimento que os ideólogos da reforma da educação têm sobre a escola. Para eles, a escola é o lugar de ensinar cidadania e qualificar para o trabalho por meio das competências e, por isso, não é necessário apropriar-se do conhecimento, já que este é rapidamente superado.

Dessa forma, o desenvolvimento das competências torna-se objetivo primordial a ser buscado pelo novo Ensino Médio e esse processo em substituição 
às especializações tradicionais, tendo em vista as transformações no mundo do trabalho e da vida trazidas pelas novas tecnologias, demandando novos aprendizados e requalificações constantes, tornaram-se os fundamentos pedagógicos dos PCNEM.

O conceito de competência, no entanto, não tem sua origem na educação, mas sim, na organização do trabalho na fábrica, no momento da crise do fordismo e o aparecimento do Toyotismo. A remuneração fordista se dava pelo posto de trabalho, pois se tratava de um trabalhador com habilidades específicas. Essa concepção entra em crise e, em seu lugar, adota-se um modelo mais flexível, por meio do qual se requer alguém que saiba fazer muitas operações, sem um posto determinado para trabalhar. Hirata capta o momento dessas mudanças. Para ela:

A competência é uma noção oriunda do discurso empresarial nos últimos dez anos e retomada em seguida por economistas $e$ sociólogos na França [...] o modelo da competência corresponderia a um novo modelo, pós-taylorista, de qualificação no estágio de adoção de um novo modelo, pós-taylorista, de organização do trabalho e de gestão da produção. Sua gênese estaria associada à crise da noção de postos de trabalho, e a de um certo modelo de classificação e de relações profissionais. A adoção do modelo da competência implica um compromisso pós-taylorista, sendo difícil de pôr em prática se não se verificam soluções (negociadas) a toda uma série de problemas, sobretudo o de um desenvolvimento não remunerado das competências dos trabalhadores na base da hierarquia, trabalhadores estes levados no novo modelo de organização do trabalho a uma participação na gestão da produção, a um trabalho em equipe e a um envolvimento maior nas estratégias de competitividade da empresa, sem ter necessariamente uma compensação em termos salariais (HIRATA, 2003, p.133).

Uma escola organizada a partir desses princípios é assumidamente uma escola que se insere no pós-fordismo e que, portanto, não forma especialista. Ela forma o cidadão competente, capaz de exercer um amplo conjunto de funções no seu local de trabalho, enfim, um tarefeiro. Mas quem é esse trabalhador competente? Para Jacomeli:

O trabalhador "competente" ou "flexível" é aquele que desenvolve atitudes voltadas para a resolução de problemas, que se adapta a 
qualquer situação no ambiente de trabalho, sabendo trabalhar em equipe. A escola, em qualquer momento da vida do indivíduo, deve prepará-lo para a aquisição de competências básicas (JACOMELI, 2004, p.51).

As competências tornaram-se, pois, a razão de ser da escola do Ensino Médio. Sua aquisição é a condição para o acesso ao emprego e consequentemente à cidadania. A escola dedica-se, portanto, ao desenvolvimento das competências básicas tanto para o exercício da cidadania, quanto para o exercício profissional. Os PCNEM consideram como uma das principais competências a serem desenvolvidas a:

Capacidade de abstração, desenvolvimento do pensamento sistêmico, ao contrário da compreensão parcial e fragmentada dos fenômenos, da criatividade, da curiosidade, da capacidade de pensar múltiplas alternativas para a solução de um problema, do desenvolvimento do pensamento divergente, da capacidade de trabalhar em equipe, da disposição para procurar e aceitar críticas, da disposição para o risco, do desenvolvimento crítico, do saber comunicar-se, da capacidade de buscar conhecimento (BRASIL, 1999, p.24).

Essas competências, que devem ser trabalhadas nas escolas de Ensino Médio, explicam o exposto anteriormente por Hirata (2003) ao abordar a passagem do fordismo para o Toyotismo no que se refere à mudança da organização do trabalho. O fim do especialista no universo da produção e o aparecimento do trabalhador multifuncional escondem uma forma perversa de exploração deste trabalhador, por meio da mais-valia. Ao exercer múltiplas tarefas, o trabalhador é transformado em tarefeiro, pois o fato de substituir a muitos, não implica aumento da sua remuneração na mesma proporção do trabalho executado e das responsabilidades assumidas.

O Relatório da UNESCO e os PCNEM pautam-se pelo conjunto de competências que o modelo Toyota considera adequado para a organização do trabalho no atual estágio do capitalismo. Tanto o primeiro quanto o segundo, 


\section{Revista Sul-Americana de Filosofia e Educação - RESAFE}

criticam o conhecimento escolar. Com relação ao primeiro, vale destacar que sua crítica parte do seguinte pressuposto:

Contesta-se a pertinência dos sistemas educativos criados ao longo dos anos - tanto formais como informais - e sua capacidade de adaptação é posta em dúvida. Estes sistemas, apesar do extraordinário desenvolvimento da escolarização mostram-se, por natureza, pouco flexíveis e estão à mercê do mínimo erro de participação, sobretudo quando se trata de preparar competências para o futuro (DELORS, 2006, p.107).

Para o segundo documento, a educação não deve ser duradoura como nos modelos vigentes, ao enfatizar que "o significado de educação geral no nível médio, nada tem a ver com o ensino enciclopédico e academicista dos currículos tradicionais" (BRASIL, 1999, p.85-86).

Essa crítica apontada pelos dois documentos evidencia a necessidade de se distanciar da concepção de educação que tinha como objetivo a formação do especialista, próprio do modelo fordista de organização do trabalho.

É nessa perspectiva de estabelecer novos parâmetros para a educação que Perrenould (2005) organiza sua razão contra os conteúdos difundidos pela escola, afirmando que os programas curriculares "são sobrecarregados demais e induzem os professores a privilegiar a transmissão eficaz de um grande número de conhecimentos em detrimento de uma construção comum em um procedimento de projeto e de debate" (PERRENOUD, 2005, p.40).

Trabalhar por projetos é na verdade, em sua proposta, fazer estudos de casos e como tal expressar-se pela individualidade. Ora, a transmissão do conhecimento teórico se expressa pela generalidade. É necessário portanto, que o professor transmita o conhecimento para que o aluno aprenda na sua relação com os outros e com o professor.

Perrenoud assume uma posição contrária à transmissão de conteúdos porque ele entende o aluno como indivíduo e não como Ser. Compreender o aluno como indivíduo é próprio do pós-modernismo. Entretanto, indivíduos não aprendem, pois somente o Ser é capaz de aprender, porque a educação é 
ontológica e, portanto, a aprendizagem só acontece entre Seres. Por isso é necessário que o professor transmita o conhecimento produzido pela humanidade para que os alunos se apropriem desse conteúdo e se desenvolvam. Sendo assim, só o professor é capaz de tirar o aluno da singularidade e levá-lo para a generalidade. Aí se dá a aprendizagem. (ALMEIDA, 2001) Contrapondo-se a Perrenoud, Duarte deixa clara a necessidade da transmissão do conhecimento pelo professor para que o aluno aprenda e se desenvolva ao afirmar que:

O desenvolvimento sociocultural do indivíduo é o desenvolvimento de um indivíduo histórico, portanto situado na história social humana. Para que esse desenvolvimento ocorra é necessário que o indivíduo se aproprie dos produtos culturais, tanto aqueles da cultura material como aqueles da cultura intelectual. Essa apropriação da cultura pela criança é mediatizada pelos adultos que já se apropriaram da mesma cultura, isto é, o processo de apropriação é um processo mediatizado, um processo que exige a interação entre adultos e crianças (DUARTE, 2003, p.44).

O ser humano não é. Ele será. Quanto mais conhecimento ele se apropriar, mais desenvolvido ele será. Em sentido oposto, o sociólogo suíço afirma que "é preciso abrir mão de dois terços das noções ensinadas, ir ao essencial, para construí-lo mais lentamente, progressivamente, dialeticamente, no tateio, na busca e no debate" (PERRENOUD, 2005, p.54).

Ora, os pais dos alunos, principalmente os mais pobres, têm consciência de que o acesso ao conhecimento é necessário para melhorar o futuro dos seus filhos, gerando novas oportunidades. Nesse sentido, o papel do professor é garantir que o conhecimento seja apropriado pelos seus alunos, sem os quais eles não terão como participar da tal sociedade do conhecimento. E o papel da escola, ao contrário do que afirma Perrenoud é "possibilitar o acesso das novas gerações ao mundo do saber sistematizado". (SAVIANI, 1991 p.80).

Em síntese, a modificação procedimental de rígidos para os flexíveis, atingiu os setores da vida produtiva e social nas últimas décadas, exigindo o aprimoramento das habilidades comportamentais e cognitivas como: criatividade diante de situações desconhecidas, análise, estabelecimento de relações, síntese, rapidez de respostas e, comunicação clara e precisa. Além disso exigiu interpretação e uso de várias formas e linguagens, capacidade para trabalhar em 


\section{Revista Sul-Americana de Filosofia e Educação - RESAFE}

grupo, gerenciar processos, eleger prioridades, criticar respostas, avaliar procedimentos, resistir a pressões, enfrentar mudanças permanentes, aliar raciocínio lógico-formal à intuição criadora, estudar continuamente, e assim por diante.

Essas mudanças no âmbito da produção chegam à escola e se configuram numa nova pedagogia, conforme afirma Kuenzer, (2004, p. 87): "No que tange à nova pedagogia, ela encontra sua melhor expressão na pedagogia das competências". A pedagogia das competências é a expressão do modelo produtivo configurado na perspectiva Toyota e, portanto, é a nova pedagogia a serviço do capital. Desse modo, a assim chamada pedagogia das competências é, na verdade, a pedagogia Toyota. Essa forma de compreender a educação está presente em todo o texto dos PCNEM.

Posto isso, como fica a formação dos professores? Ela sobrevive sem teoria? Formar para quê, se o saber teórico tem cada vez menos espaço na escola? A razão está sendo expulsa de todas as esferas da vida social. Nem na academia, o templo do saber, a razão encontra espaço como outrora.

O modelo de organização do trabalho se modificou e o currículo escolar também foi modificado para atender às demandas do capital que necessita de um trabalhador de novo tipo. É nessa perspectiva que as Políticas de Formação Docente vão se adequando às Novas Políticas Educacionais, ajustadas ao sistema. Assim, as Escolas Públicas são transformadas em verdadeiras agências formadoras de mão de obra e os alunos, usuários desse nível de Ensino, tem suas competências treinadas para entrar imediatamente no mercado de trabalho. Desse modo, o processo educativo vai aos poucos se distanciando do Homo Sapiens e se constituindo no Homo Faber.

Os cursos que formam professores diminuem a sua carga horária enfatizando a prática em detrimento da teoria e a separação entre o pensar e o fazer, gerando seres alienados.

A separação entre o pensar e o fazer, característico do fordismo, permanece no novo modelo, embora o conjunto de atividades diferentes desempenhado pelo 
mesmo trabalhador seja diferente do especialista do modelo anterior. Naquele, predominava o especialista e neste o multifuncional.

Propostas como estas que se renderam aos interesses do capitalismo devem ser combatidas à exaustão, contrapondo-a com a emancipação humana, também por meio da difusão e desenvolvimento do conhecimento. Uma educação que forma para o trabalho, está comprometida com a burguesia e com os interesses do capital. É necessário desenvolver integralmente os indivíduos para que possam superar o capital e suas categorias e conceitos abstratos como desenvolvimento integral, educação libertadora, crítica, humanizadora, etc.

Uma escola que trabalha na perspectiva da emancipação humana, difunde o que a humanidade produziu de melhor em termos de conhecimento científico para formar uma sociedade de homens livres e autônomos. O ser humano autônomo é aquele que consegue fazer o que pensa e pensar o que faz, ou seja, é capaz de desenvolver uma práxis criativa.

\section{Conclusões}

A burguesia enquanto classe social dominante, precisa de indivíduos dispostos a manter a atual estrutura. A escola é o lugar em que essas pessoas são treinadas para desempenharem seu papel na sociedade. Se ocorrer alguma falha, serão responsabilizados por ela. Essa referida classe social concebe a sociedade como um conjunto de engrenagens e quando há problemas, troca-se a peça para continuar girando. Assim, indivíduos que não funcionam são descartados.

Em uma sociedade mercantilizada como a burguesa, os cursos para treinamento de competências tornaram-se oportunidade de mais um negócio, pois os indivíduos estão sempre dispostos a comprar mais um kit competência para não perderem a sua função na engrenagem, mesmo que essa condição jamais seja percebida em sua consciência.

Quando não há manifestações que indiquem a existência de problemas, significa que as peças da engrenagem estão funcionando muito bem. É a certeza de que o processo de dominação está eficiente e que, desse modo, os meios que 
difundiram os valores que caracterizam esse ser humano cumpriram o seu papel. A escola cumpriu bem a sua função.

Por isso, tanto a escola quanto o Estado e o próprio modo de produção capitalista precisam ser destruídos e não reformados.

Choque de gestão, democratização da escola, participação da comunidade, protagonismo juvenil, reforma do Estado, são algumas propostas permitidas pela burguesia por expressarem ajustes que não produzem efeitos significativos para melhorar a vida da maioria da população.

Essas mudanças são admissíveis com o objetivo de corrigir algum detalhe defeituoso do modo de produção capitalista mantendo intactas as estruturas fundamentais da sociedade como um todo, em conformidade com as exigências inalteráveis da lógica do capital. Assim, ao adotar o expediente reformista, seus proponentes estão defendendo a manutenção do capitalismo e postulando uma mudança gradual na sociedade. Porém, o objetivo real do reformismo é fazer os ajustes ao modo de produção e impedir o desenvolvimento de processos revolucionários e assim, impedir uma possível superação desse modo de produção.

A redução do conhecimento teórico no currículo escolar contribui de forma significativa para manter esse quadro ajustado ao capital. O recuo teórico aparece no momento em que a fragmentação da realidade, do ser humano e do conhecimento se aprofunda na medida em que também se aprofunda a precarização no mundo do trabalho. Esta precarização não é diferente no trabalho docente. Ela se acentua em tempos de globalização, de neoliberalismo e pósmodernismo ganhando contornos sem precedentes na história.

Conceber a sociedade de forma fragmentada não é nenhuma novidade para a pós-modernidade. A fragmentação das relações sociais é uma necessidade do sistema capitalista e ao aproximar-se desse ideário sem confrontá-lo, ficará muito difícil manter o conhecimento, a escola e o professor.

Fragmentar é perder a perspectiva histórica, por que mergulha na realidade alienada e se recusa a olhar o horizonte com perspectivas de continuidade. Em tempos de recuo da teoria, dessa globalização, do neoliberalismo e do pósmodernismo a formação dos professores deve se ancorar na busca constante pelo 
que de melhor o homem produziu ao longo de sua história, o conhecimento. Organizá-lo e transmiti-lo para seus alunos, desenvolvendo assim um ser humano livre e universal, capaz de compreender os movimentos na história e substituir o sistema que nos impede de sermos integralmente humanos. Assim, urge lutar pela emancipação humana por meio do conhecimento científico, ensinando o máximo possível. Nesse sentido, transformar cada aula no nosso melhor momento é um ato revolucionário.

Esta é uma tarefa para quem acredita no homem enquanto totalidade e não como fragmento. Olhar nesta perspectiva é acreditar que é possível educar para o futuro que acontece todos os dias na vida de cada um. Este é o nosso desafio.

\section{REFERÊNCIAS}

ALMEIDA, José Luis Vieira de. Tá na rua: representações da prática dos educadores de rua. São Paulo, Xamã editora, 2001.

ANTUNES, Ricardo. Os sentidos do trabalho - Ensaio sobre a afirmação e a negação do trabalho. $7^{\mathrm{a}}$ reimp. São Paulo, Boitempo editorial, 2005.

ARROYO, Miguel. As relações sociais na escola e a formação do trabalhador. In: FERRETI, Celso João. et. al. Trabalho, formação e currículo - para onde vai a escola? São Paulo, Xamã, 1999. p. 13-41.

BRASIL. Secretaria de Educação Média e Tecnológica. Parâmetros Curriculares Nacionais: ensino médio. Brasília: MEC/SEMTEC, 1999.

. Secretaria de Educação Fundamental. Parâmetros Curriculares Nacionais: introdução aos parâmetros curriculares nacionais. Brasília: MEC/SEF, 1998.

BUTLER, Eamonn. A contribuição de Hayek às ideias políticas e econômicas de nosso tempo. Tradução de Carlos dos Santos Abreu. Rio de Janeiro: Instituto Liberal, 1987.

COSTA, Frederico. Elementos de compreensão do pensamento pós-moderno: o irracionalismo como subproduto da crise do capital. In JIMENES, Susana Vasconcelos e RABELO, Jackline (Orgs) Trabalho, Educação e Luta de Classes: A pesquisa em defesa da história, Fortaleza, Brasil Tropical, 2004. 
DELORS, Jacques (et. Al.). Educação: um tesouro a descobrir. Relatório para a UNESCO da comissão internacional sobre educação para o século XXI. $6^{a}$ ed. São Paulo: Cortez. Brasília: MEC: UNESCO, 2001.

DUARTE, Newton. Sociedade do conhecimento ou sociedade das ilusões? Quatro ensaios crítico-dialéticos em filosofia da educação. Campinas, Autores Associados. 2003

- (Org.) A rendição pós-moderna à individualidade alienada e a perspectiva marxista da individualidade livre e universal. In: DUARTE, Newton. Crítica ao fetichismo da individualidade. Campinas, Autores Associados, 2004.

GROPPO, Luis Antonio. Das origens ao colapso do Estado de Bem-Estar: uma recapitulação desmistificadora. Revista HISTEDBR On-line, Campinas, n.20, p. 68 -75, dez. 2005 -ISSN: 1676-2584

HIRATA, Helena. Da polarização das qualificações ao modelo da competência. In: FERRETI, Celso João. et. al. Novas tecnologias, trabalho e educação: um debate multidisciplinar. 9. ed. Petrópolis: ed. Vozes, 2003.

JACOMELI, Mara Regina Martins. Dos Estudos Sociais aos Temas Transversais: uma abordagem histórica dos fundamentos teóricos das políticas brasileiras (19712000). 2004. 195 f. Tese (Doutorado em Educação) - Universidade Estadual de Campinas - Faculdade de Educação. Campinas, 2004.

KUENZER, Acácia Zeneida. Exclusão includente e inclusão excludente: a nova forma de dualidade estrutural que objetiva as novas relações entre educação $e$ trabalho. In: Capitalismo, trabalho e educação. $2^{\text {a }}$ ed. rev. Lombardi, José Claudinei. et. al. Campinas: autores associados/HISTEDBR, 2004. p. 77-95.

MORAES, Maria Célia M. de. (Org.) Recuo da teoria. In: Iluminismo às avessas: produção de conhecimento e políticas de formação docente. Rio de Janeiro, DP\&A ed. 2003. p. 151-167

PERRENOULD, Philippe. Escola e Cidadania: o papel da escola na formação para a democracia. Porto Alegre: Artmed editora. 2005.

SAVIANI, Dermeval. Pedagogia histórico-crítica: primeiras aproximações. Campinas: Autores Associados, 1991. 